\title{
BIPÍTULO UI
}

A GONSTIIUIGITO DA REPÚBLIGA FEDERATIUUA DO BRASIL DE

1988 E O REEONHEEIMENTO OA GIDADANIA PARTIGIPATIUA

DOI: http://dx.doi.org/10.18616/estadodir06

Márcio José Cabral

Reginaldo de Souza Vieira

sumínio 


\section{INTRODUÇ̃̃̃O}

A cidadania possui múltiplos significados, motivo pelo qual não podemos generalizá-la ou atribuir-lhe um status que não possuía no contexto histórico e no local de sua formulação. Portanto, seus significados variam de acordo com os fatores econômicos, sociais e culturais de cada sociedade e em cada época.

Na concepção do Estado Social Democrático de Direito (GARCIAPELAYO, 2009), a cidadania acabou se constituindo em um caráter tão representativo quanto participativo. Entende-se que ser cidadão requer uma ideia mais elástica, abrangendo não apenas o direito ao voto, mas também a participação nas esferas sociais, o que requer um diálogo mais intenso entre Estado e sociedade, público e privado, com o objetivo de alcançar acesso nas discussões de interesse coletivo, em especial nas mais diversas espécies de políticas públicas (VIEIRA, 2013; PILATI, 2012).

Entende-se também que, em relação aos direitos, a cidadania pode ser exercida de forma direta, por meio da participação do cidadão na construção e no uso desses direitos, ou, como concebida no paradigma moderno (em especial no modelo liberal), de forma indireta, quando o cidadão se faz representar por terceira pessoa, ou seja, por representantes políticos escolhidos, em regra, pelo exercício do voto direto.

Nessa conceituação (liberal), percebe-se que o cidadão nada mais é que um indivíduo detentor de direitos eleitorais, ou seja, da prerrogativa de votar e ser votado, bem como de exercer cargos públicos. Entretanto, o paradigma que sustenta esse modelo representativo encontra-se em crise em seus aspectos sociais, políticos e jurídicos.

Por conseguinte, é essa crise do paradigma moderno que fundamenta o escopo desta pesquisa: investigar se a Constituição da República Federativa do Brasil de 1988, a partir da concepção do Estado Social e Democrático de Direito, reconheceu a existência de uma cidadania participativa ao lado da cidadania representativa construída pelo paradigma moderno (com ênfase em sua matriz liberal). 
Para tanto, o estudo foi dividido em duas partes: na primeira, partindo da noção de paradigma, analisa-se a superação do modelo representativo liberal; já na segunda parte, tendo em vista as formulações do texto da Constituição da República Federativa do Brasil de 1988 (CRFB/1988) e da concepção de Estado Social e Democrático de Direito, reflete-se o reconhecimento no texto constitucional da cidadania participativa.

No que tange aos procedimentos metodológicos adotados, parte-se de um estudo interdisciplinar, no qual se utiliza o método dedutivo, com análise descritiva e qualitativa, por meio da técnica de pesquisa bibliográfica.

\section{A SUPERAĞ̃̃o do PARADIGMA REPRESENTATIVO MODERNO LIBERAL}

A Constituição da República Federativa do Brasil, de 1988, criou um novo paradigma, que é o da participação popular nas decisões do Estado brasileiro.

Para entendermos melhor essa mudança, precisamos conceituar, inicialmente, o termo "paradigma". Para tanto, nos valemos das palavras de Kuhn (1997, p. 13): “[...] considero 'paradigmas' as realizações científicas universalmente reconhecidas que, durante algum tempo, fornecem problemas e soluções modelares para uma comunidade de praticantes de uma ciência".

Desta forma, com base nas palavras de Kuhn (1997), essa compreensão majoritária e estabelecida como verdade por um grupo de cientistas sobre o funcionamento de determinado mecanismo passa a ser entendida como paradigma, nos diversos campos da ciência.

Para Morin e Le Moigne (2000), quando existe a proposição de um novo paradigma não se está propondo uma alternativa, mas um complemento ao que se havia estabelecido como verdade. Esse complemento seria, na essência, uma aventura emancipadora, e não uma negação do 
passado e todo o conhecimento científico realizado até o momento da apresentação da nova alternativa.

E é esse o contexto da crise do modelo da cidadania representativa e de seu paradigma estruturante que dá sustentação ao surgimento ou coexistência de um novo paradigma (VIEIRA, 2013).

Morin (2011, p. 41) denomina esse cenário de crise de paradigma, ou seja, afirma que "[...] estamos num período 'entre dois mundos'; um que está prestes a morrer, mas que não morreu ainda, e outro, que quer nascer, mas que não nasceu ainda. Estamos numa grande confusão, num desses períodos angustiantes".

Santos (2001) assevera que os paradigmas são passageiros e construídos historicamente e a contemporaneidade está presenciando uma transição deles, já que os conflitos e contradições do paradigma dominante não conseguem ser mais geridos e resolvidos. A esses dois paradigmas, o autor denomina modernidade (dominante e em crise) e pós-modernidade (o próximo a ser vivenciado).

Segundo Bonavides (1995, p. 361):

[...] o descrédito do princípio representativo no Brasil atual testifica tão somente a crise de um sistema de representação divorciado do sentimento nacional, em razão de alojar nas assembleias legislativas e nas duas Casas do Congresso uma classe política sem ética, de cujas entranhas nasceram lideranças corruptas, constantemente apartadas dos mais elevados interesses nacionais e sem nenhuma afinidade com os sentimentos generalizados nas camadas sociais esmagadas e empobrecidas.

Ocorre que, mesmo diante dessa realidade, a cidadania representativa é encarada e utilizada como a única forma de atuação popular, sendo as outras formas de cidadania (participativa e semidireta) pouco utilizadas e lembradas, legitimando, assim, a reprodução do círculo vicioso da apatia política. 
Como bem assevera Mezzaroba (2004), essa ideia arraigada na sociedade da representação política, vinculada à imagem do representante como "salvador" de todos os males, está imposta devido a fatores históricos que fortaleceram essa cidadania, a qual objetiva a não participação das pessoas nos acontecimentos sociais, pois há a crença de que já cumpriram sua missão de cidadão no exercício do voto.

A quebra desse paradigma representativo encontra caminhos árduos, que esbarram, inclusive, na falta de habitualidade do cidadão em se ver senhor de direitos na construção conjunta com o Estado de todas as políticas públicas que venham a afetá-lo.

Não se defende o fim da democracia representativa, mas a convivência entre o paradigma representativo e o participativo (VIEIRA, 2013).

Como bem lembra Benevides (2000, p. 45), o grande problema quando se debate acerca da temática da cidadania diz respeito à rivalidade que se cria entre a representação e a participação, trazendo de maneira implícita "uma alternativa radical, ou uma ou outra", não se considerando a possibilidade da convivência harmoniosa de ambas no sistema político brasileiro por meio de um "sistema misto".

No entender de Pilati (2012), a autonomia do coletivo em relação ao público estatal começa pelo resgate da soberania participativa constitucional. Isso implica a transformação dos elementos da relação jurídica tradicional nos três planos: do sujeito, do objeto e do fato ou exercício dos direitos, por incluir a dimensão coletiva. Impõe e importa também a autonomia política local, como espaço por excelência das práticas democráticas.

Para que se consiga pensar para além da cidadania representativa, é necessário, portanto, o rompimento com concepções até então tidas como imutáveis, e essa percepção somente será sentida a partir do momento em que a própria sociedade, por meio de ações participativas, conseguir visualizar o poder que possui em suas mãos quando se trata da conquista e exercício de direitos. 
A partir da tensão paradigmática, Wolkmer (2001, p. 16) afirma:

Que se parte da percepção de crise e de esgotamento do modelo jurídico liberal-individualista, que não oferece respostas satisfatórias (eficazes) aos reclamos político-sociais de segurança e certeza no atual estágio de evolução das sociedades complexas e conflitivas de massa. Impõe-se, como condição básica, a demarcação de um novo fundamento de validade para o mundo jurídico, um paradigma que incida, inexoravelmente, no reconhecimento de novas formas de ações participativas.

Esse novo fundamento, que reconhece e legitima outras maneiras de atuação para além daquela emanada pelo Estado, o autor denomina pluralismo jurídico, indo de encontro ao monismo, até então tido como única fonte de criação do Direito (WOLKMER, 2001).

Com isso, o pluralismo das formas políticas e jurídicas acaba ganhando fôlego e procurando se estabelecer como premissa maior, na qual a cidadania representativa não consegue mais se estabelecer de modo exclusivo, abrindo caminho para o predomínio do ideário participativo, cuja força está, justamente, em não ignorar os anseios da sociedade, contrapondo-se ao ideário individualista, razão pela qual se torna necessária a soma de outras formas de participação para a condução dos destinos do Estado.

Para Pilati (2012, p. 161), a dificuldade, talvez a maior, é conseguir deslocar a discussão até aquele ângulo de observação que permite olhar para fora do paradigma hegemônico. Isso é difícil porque pensamentos arraigados por uma cultura jurídica secular não se modificam de uma hora para outra.

Portanto, pensar para além da cidadania representativa exige um exercício diário de reinvenção cotidiana dos espaços, razão pela qual os instrumentos participativos devem estar sempre disponíveis para as pessoas, fazendo com que elas se sintam ouvidas e, consequentemente, tornem-se protagonistas de sua história. 
Para fortalecer a ideia de cidadania participativa, Guarinello (2003) ressalta uma característica da cidadania antiga, tanto nos modelos democráticos quanto naqueles de origem oligárquica ou aristocrática: ela era exercida diretamente, sem a existência de intermediários ou representantes.

Em uma reflexão sobre o tema, Comparato (2006, p. 197) versa que os antigos conheceram e exerceram a cidadania em um cenário de democracia direta (mesmo com as limitações existentes). Já os modernos construíram e desenvolveram a cidadania dentro do modelo da democracia representativa que "deu origem à democracia formal", caracterizando-se, "na realidade, um claro impedimento à soberania do povo".

Além disso, nos primeiros, a cidadania estava vinculada ao seu pertencimento àquela sociedade (sem a dicotomia sociedade civil e sociedade política, construída na modernidade), que encarnava em si a civitas ou cidade-estado; já nos modernos, a cidadania é originária do vínculo com o Estado (VIEIRA, 2013; PILATI, 2012).

Bobbio (2000, p. 372), ao analisar a democracia antiga e a moderna, afirma que "Democracia significava o que a palavra designa literalmente: poder do demos e não, como hoje, poder dos representantes do demos." A participação dos cidadãos ocorria na ágora (praça), onde deliberavam os assuntos que interessavam ao coletivo.

Nesse sentido:

[...] enquanto hoje a eleição é a regra e a participação direta a exceção, antigamente a regra era a participação direta, e a eleição, a exceção. Poderíamos também dizer da seguinte maneira: a democracia de hoje é uma democracia representativa às vezes complementada por formas de participação popular direta; a democracia dos antigos era uma democracia direta, às vezes corrigida pela eleição de algumas magistraturas. (BOBBIO, 2000, p. 374). 
Observa-se, pela reflexão de Bobbio, que as deliberações sobre os destinos das cidades ocorriam nas assembleias, nos julgamentos, entre outros atos de participação direta do cidadão, momento em que o ponto de vista individual era submetido ao coletivo. Tais situações não alcançam o ideário moderno liberal, no qual o indivíduo é livre na esfera privada, exercendo soberania apenas na aparência.

Entende-se ser este o paradigma a ser vencido, fato que nos leva às linhas que adiante seguem e que nos mostram o caminho do acolhimento das ideias de cidadania participativa, em especial na Carta Constitucional Brasileira de 1988.

\section{O RECONHECIMENTO DA GIDADANIA PARTICIPATIVA NA GRFB/1988}

A Constituição Federal, promulgada em 5 de outubro de 1988, trouxe três mecanismos que possibilitaram a relação do povo com o Estado, sendo eles a cidadania representativa, a semidireta e a participativa, visando assegurar, com isso, o exercício dos direitos sociais, a igualdade e a justiça a todos os seus cidadãos, adiantando-se muito ao simples voto direto da democracia representativa.

Com a conquista do Estado Social e Democrático de Direito, em 2009, a cidadania acabou se revestindo de caráter tanto representativo quanto participativo, buscando resgatar a inserção da sociedade nos espaços públicos, permitindo que a soberania estatal representativa e a coletiva participativa convivessem lado a lado, sendo essa situação nominada por Vieira (2013, p. 153) como "[...] a coexistência de duas esferas de soberania".

Para Bonavides (1995, p. 355), a participação do cidadão nas decisões estatais trata-se do "[...] povo investido na amplitude real de seu poder de soberania, alcançando, pela expressão desimpedida de sua vontade regulativa, o controle final de todo o processo político". 
O artigo 1으 caput da Constituição Federal de 1988 previu que a República Federativa do Brasil constitui-se em Estado Democrático de Direito ${ }^{1}$, significando um avanço em termos de respeito aos Direitos Humanos e às garantias fundamentais (BRASIL, 1988).

Para que tudo isso seja possível, não há que se negar a mensagem subliminar, contida no artigo em tela, da necessidade da participação popular por meio das ações de cidadania participativa, a fim de que tudo tome corpo prático.

O Estado Social Democrático de Direito objetiva, então, a inserção da lei num contexto instrumental, de maneira não totalitária, com o cidadão podendo disponibilizar-se do aparelho estatal.

Novamente tendo como referência o artigo 10 da CFRB/1988, encontramos amparados em seu texto a soberania (Inciso I), a cidadania (Inciso II), a dignidade da pessoa humana (Inciso III), os valores sociais do trabalho e da livre iniciativa (Inciso IV), além do pluralismo político (Inciso V), demonstrando a preocupação do Estado para com valores diferentes, não verificados no regime autoritário havido anteriormente em nosso país (BRASIL, 1988).

Dentre os instrumentos de cidadania, o mesmo dispositivo, em seu parágrafo único, elencou três tipos, sendo eles a representativa, semidireta e a participativa, construindo assim uma nova concepção, não limitada apenas a aspectos relativos ao direito de votar e ser votado (BRASIL,1988).

De acordo com Vieira (2013), a cidadania, mesmo de caráter representativo, mantém presença na Constituição de 1988 por meio da escolha, pelo voto direto e secreto, dos membros dos poderes executivo e legislativo, igualando esse direito (o do voto) para todos os cidadãos brasileiros.

Na cidadania semidireta, por outro lado, o povo interfere, conforme artigo 14 da Constituição Federal de 1988, porém por meio do campo

1 Entende-se, para este estudo, que a Constituição da República Federativa do Brasil de 1988, apesar de nomear Estado Democrático de Direito em seu artigo 1으, adotou em sua concepção um sentido mais amplo, que nomeamos, com base em Garcia-Pelayo (2009), Estado Social e Democrático de Direito. 
legislativo, ou seja, por plebiscito (Inciso I), referendo (Inciso II) e iniciativa popular (Inciso III) (BRASIL, 1988).

Tanto o plebiscito quanto o referendo são instrumentos de manifestação popular, sendo que, em ambos os casos, o povo é ouvido. Porém essa oitiva se dá em momentos distintos, pois enquanto no primeiro a sociedade se manifesta antes da criação de uma lei, no segundo, a consulta popular é sobre a lei já aprovada.

Por fim, a iniciativa popular trata-se de um processo de participação mais complexo que os demais instrumentos, posto que envolve desde a “[...] elaboração de um texto até a votação de uma proposta, passando pelas várias fases da campanha, coleta de assinaturas e controle da constitucionalidade." (BONAVIDES, 1995, p. 369).

Assim, o que se consta é que:

Além da democracia representativa e da semidireta, a Constituição Federal de 1988 dispõe também da chamada democracia participativa, que apesar de se contrapor à representação no que diz respeito ao exercício direto da cidadania, a partir das manifestações coletivas da Sociedade, o paradigma participativo não renega a existência da democracia representativa, mas apenas Ihe retira a exclusividade como lócus do exercício da cidadania. Deste modo, teremos uma coabitação entre o paradigma moderno representativo e o paradigma participativo pós-moderno. (VIEIRA, 2013, p. 180).

Conforme Pilati (2012, p. 164), a autonomia do coletivo em relação ao público estatal começa pelo resgate da soberania participativa constitucional. Isso implica a transformação dos elementos da relação jurídica tradicional, nos três planos: "[...] do sujeito, do objeto e do fato ou exercício dos direitos, por incluir a dimensão coletiva. Impõe também a autonomia política local, como espaço das práticas democráticas". 
A ideia da autonomia política local talvez seja um dos pressupostos principais da concepção de cidadania participativa, pois possibilita a solução dos problemas de acordo com a visão dos atores próximos ao problema, e não de atores distantes que acabam decidindo, em muitas oportunidades, sem o conhecimento da realidade local.

Conforme Bonavides (1995, p. 378), “[...] deixa de existir, a dualidade governantes-governados, do estilo tradicional, para emergir a unidade do corpo político, com todos os governados sendo ao mesmo passo governantes.", ou seja, da relação hierarquizada, passa-se para uma relação de parceria, com todos atuando num espaço de cogestão na caminhada pela concretização de objetivos comuns.

De acordo com Vieira, (2013, p. 180), com as várias facetas de cidadania efetivadas em nossa constituição, teremos uma coabitação entre o paradigma moderno representativo e o paradigma participativo pós-moderno.

Observa-se também que a própria CRFB/1988 foi elaborada num cenário de mobilização e participação social, resultando num documento de caráter democrático, já que acolhe em seu texto a democracia representativa, semidireta e participativa enquanto instrumentos disponíveis para a participação da sociedade.

Nesse ponto, para Bonavides (1995) a CRFB/1988 avançou para além das expectativas, pois nenhuma outra norma jurídica trouxe a provisão de uma cidadania participativa, cabendo agora outro trabalho: a sua concretização material.

Enfatiza o autor que, do ponto de vista formal, já foram abertas, como se vê, no constitucionalismo brasileiro vigente, as portas ao ingresso e à introdução no sistema participativo de meios bastante avançados de democracia direta (BONAVIDES, 1995).

Há, na Constituição mesma, pressupostos cuja eficácia aplicativa vai depender largamente do sentido e da direção que o processo político venha a tomar em termos de harmonia e correspondência do poder com a cidadania (BONAVIDES, 1995, p. 352). 
De acordo com Almeida (2012, p. 3):

A Constituição Federal de 1988 adota, em grandes linhas, uma perspectiva comunitária, ao abrigar e expressar a preocupação com valores éticos - próprios do enfoque da comunidade - na regulamentação de um extenso rol de direitos fundamentais e na implementação de instrumentos judiciais para sua garantia. Na perspectiva constitucional, a participação cidadã e a solidariedade dos membros da comunidade exercem papel fundamental para o desenvolvimento da democracia, e o município é ambiente propício ao fortalecimento da comunidade e a sua integração nas políticas públicas. A eficácia obtida pelas políticas públicas a partir da interação entre o poder público e a comunidade no enfrentamento dos problemas sociais, depende do capital social e é na esfera local que este melhor se desenvolve.

Conforme Bastos (2002), o Estado Democrático de Direito deve romper com a indiferença social e a apatia política gerada e reproduzida historicamente, caso queira que a sociedade exerça a cidadania participativa, e isso somente ocorrerá no momento em que ela se sentir parte responsável pelos fatos que ocorrem no seu dia-a-dia.

A cidadania participativa implica "[...] que o povo tenha ao seu imediato dispor, para o desempenho de uma desembaraçada e efetiva participação, os instrumentos de controle da mesma." (BONAVIDES, 1995, p. 354), ou seja, não significa um conjunto de pessoas agindo sozinhas, de modo isolado e independente do Estado, pelo contrário, trata-se de um espaço de gestão compartilhada entre as esferas federativas juntamente com a sociedade.

Sociedade e Estado são forças que devem caminhar na mesma direção, necessitando, portanto, que o conceito de cidadania participativa seja exercido em sua plenitude. 
A cidadania participativa com a qual se busca trabalhar é aquela que prioriza o compartilhamento de conhecimento e ações na busca da construção gradual e conjunta de melhores práticas em favor do universo coletivo.

Benevides (2000) destaca as vantagens de uma sociedade em que existe participação, sendo elas a educação social, pela qual o povo torna-se corresponsável pelo destino da coisa pública, o fortalecimento do regime democrático, já que as pessoas estariam em constante controle de seus atos, bem como do instrumento para aferição da vontade popular, pois possibilitaria a mobilização dos "apáticos" ou "irresponsáveis" pelas questões sociais.

Outro ponto relevante é que, ao se exercer a cidadania participativa, não se está abandonando ou sacrificando a cidadania representativa, já que esta foi uma conquista para o Estado Social e Democrático de Direito. Não se discute a sua importância no contexto populacional existente do Brasil, sendo assim, quando se fala em participação, se busca o reconhecimento de outros modos de exercício da cidadania, para além do modelo exclusivo representativo (BONAVIDES, 1995).

Na concepção de Pilati (2012, p. 30, grifo nosso):

[...] quando se visualiza apenas um modo de cidadania e o exerce como se fosse a única maneira correta de exteriorizar o status de cidadão, consequentemente se está priorizando uma política individualista, assentada na propriedade privada, no governo representativo e na crença na infalibilidade do Estado como instrumento de proteção do chamado bem comum.

Entende-se, dessa forma, que a concepção participativa da cidadania somente será fortalecida na medida em que é exercitada, diariamente, como princípio democrático, como essência cidadã e não apenas como mera vontade de um governante, tornando-se, assim, primordial para qualquer nação dita democrática. 


\section{CONGLUSÃO}

Constatou-se, nesta pesquisa, ser necessária uma nova concepção de cidadania que supere o aspecto meramente formal e representativo, incorporando, inclusive, a possibilidade de re(invenção) das formas de seu exercício.

Ao se defender essa nova concepção, não se nega a existência do paradigma representativo, erigido pelo pensamento moderno e consolidado por sua matriz liberal. $O$ que se entende, com base na pesquisa realizada, é que deve ser incorporada a matriz do paradigma participativo, inserto no texto da Constituição da República Federativa do Brasil de 1988, possibilitando, desse modo, a coexistência dos dois modelos: representativo e participativo.

Nesse sentido, é necessário rever a concepção de separação entre sociedade e Estado, como se ambos fossem antagônicos, pois esse dualismo, para não dizermos sua completa separação, marcaram ostensivamente a concepção do Estado de Direito (fruto do pensamento moderno liberal). Portanto, faz-se necessária a ampliação de espaços que permitam a participação conjunta entre sociedade e Estado, em especial na construção e no controle da implantação das políticas públicas.

Por fim, conclui-se que o reconhecimento formal e legal da cidadania participativa, com a sua inclusão constitucional na CRFB/1988, não é o suficiente para que ela se concretize. Nessa esteira, é preciso que a sociedade se organize e se mobilize para dar efetividade a esse comando constitucional, em especial no âmbito local, sob o risco, em caso de omissão, dos espaços participativos tornarem-se apenas uma simples formalidade legal. 


\section{REFERÊNGIAS}

ALMEIDA, A. P. de. O policiamento comunitário como política inovadora de segurança pública: uma análise a partir do programa nacional de segurança pública com cidadania, sob a perspectiva local de enfrentamento ao crime e à violência. 2012. 122 f. Dissertação (Mestrado em Direito) - Programa de Pós-Graduação em Direito, Universidade de Santa Cruz do Sul, Santa Cruz do Sul, 2012.

BASTOS, C. R. Curso de teoria do Estado e ciência política. São Paulo: Saraiva, 2002.

BENEVIDES, M. V. de M. A cidadania ativa: referendo, plebiscito e iniciativa popular. 3. ed. São Paulo: Ática, 2000.

BOBBIO, N. O futuro da democracia. Rio de Janeiro: Paz e Terra, 2000.

BONAVIDES, P. Teoria do Estado. 3. ed. rev. e ampl. São Paulo: Malheiros, 1995.

BRASIL. [Constituição (1988)]. Constituição da República Federativa do Brasil. Emendas Constitucionais de Revisão. Brasília, DF: Presidência da República, 1988. Disponível em: http://www.planalto.gov.br/ccivil_03/constituicao/ constituicao.htm. Acesso em: 26 nov. 2018.

COMPARATO, F. K. Repensar a democracia. In: LIMA, M. M'A. B.; ALBUQUERQUE, P. A. de M. (org.). Democracia, Direito e política: estudos internacionais em homenagem a Friedrich Müller. Florianópolis: Conceito Editorial, 2006. p. 189-224.

GARCIA-PELAYO, M. As transformações do Estado contemporâneo. Tradução de Agassiz Almeida Filho. Rio de Janeiro: Forense, 2009.

GUARINELLO, N. L. Cidades-Estados na antiguidade clássica. In: PINSKY, Jaime; PINSKY, Carla Bassanezi. História da cidadania. São Paulo: Contexto, 2003.

KUHN, T. S. A estrutura das revoluções cientificas. Tradução de Beatriz V. Boeira, Nelson Boeira. 5. ed. São Paulo: Perspectiva, 1997. 
MEZZAROBA, Orides. Introdução ao direito partidário brasileiro. Rio de Janeiro: Lumen Juris, 2004.

MORIN, E.; LE MOIGNE, J-L. A inteligência da complexidade. 3. ed. São Paulo: Peirópolis, 2000.

MORIN, E. O método 4: as ideais: habitat, vida e costumes. Tradução de Juremir Machado da Silva. 5. ed. Porto Alegre: Sulina, 2011.

PILATI, J. I. A propriedade e função social na pós-modernidade. 2. ed. Rio de Janeiro: Lumen Juris, 2012.

SANTOS, B. de S. Pela mão de Alice: o social e o político na pós-modernidade. 8. ed. São Paulo: Cortez, 2001.

VIEIRA, R. de S. A cidadania na República Participativa: pressupostos para a organização de um novo paradigma jurídico e político para os conselhos de saúde. 2013. 540 f. Tese (Doutorado em Direito) - Programa de Pós-Graduação em Direito, Universidade Federal de Santa Catarina, Florianópolis, 2013.

WOLKMER, A. C. Pluralismo jurídico: fundamentos de uma nova cultura no Direito. 3. ed. São Paulo: Alfa-Omega, 2001. 